\title{
Eficiência e viabilidade econômica do controle químico da ferrugem do eucalipto em condições de campo
}

\author{
Marcus Vinicius Masson ${ }^{1,2}$, Willian Bucker Moraes ${ }^{1}$, William Costa Matos ${ }^{2}$, Jacyr Mesquita Alves², Edson Luiz Furtado ${ }^{1}$
}

${ }^{1}$ Departamento de Produção Vegetal, Setor de Defesa Fitossanitária, Faculdade de Ciências Agronômicas (FCA) - Universidade Estadual Paulista (UNESP). Rua José Barbosa de Barros, n. ${ }^{\circ}$ 1780, Caixa postal 237, Botucatu, São Paulo, 18610-307, Brasil.

${ }^{2}$ Copener Florestal Ltda., Rua Dr. José Tiago Correia, s/n, Alagoinhas Velha, Alagoinhas, Bahia, 48030-480, Brasil.

Autor para correnpondência: Marcus Vinicius Masson (marcus.masson@yahoo.com.br)

Data de chegada: 03/04/2010. Aceito para publicação em: 25/11/2011.

\section{RESUMO}

Masson, M.V.; Moraes, W.B.; Matos, W.C.; Alves, J.M.; Furtado, E.L.. Eficiência e viabilidade econômica do controle químico da ferrugem do eucalipto em condições de campo. Summa Phytopathologica, v.37, n.2, p.107-112, 2011.

Originária da América do Sul, a ferrugem do eucalipto causada pelo fungo Puccinia psidii, vem se tornando uma doença limitante para a cultura do eucalipto no Brasil, exigindo a adoção de estratégias de controle, dentre as quais está o controle químico. Para avaliar eficiência e viabilidade econômica de fungicidas no controle da ferrugem do eucalipto, montou-se um ensaio a campo. Para a instalação do ensaio, utilizou-se o delineamento em blocos ao acaso, em esquema fatorial $3 \times 3$ ( 3 produtos e 3 doses), sendo $0,5,1,0$ e $1,5 \mathrm{~mL}$ ou g do produto comercial por litro de solução. Os tratamentos foram: 1-) Testemunha; 2-) Fungicida azoxistrobina (estrobilurina); 3-) Fungicida tebuconazol (triazol); 4-) Fungicida tebuconazol + trifloxistrobina (triazol + estrobilurina). O experimento constou de quatro repetições, com avaliação da severidade das plantas. As avaliações foram efetuadas com base no percentual de área foliar lesionada. Verificou-se que com o aumento na dosagem dos fungicidas, houve maior redução da doença nas plantas aos 7 e 15 dias pós-aplicação. O fungicida tebuconazol + trifloxistrobina a $1,5 \mathrm{~mL} / \mathrm{L}$ foi o mais eficiente contra a ferrugem do eucalipto em condições de campo. O fungicida tebuconazol apresentou maior viabilidade econômica nas três doses testadas.

Palavras-chave adicionais: Puccinia psidii; Eucalyptus; fungicidas.

\begin{abstract}
Masson, M.V.; Moraes, W.B.; Matos, W.C.; Alves, J.M.; Furtado, E.L. Economic viability and efficiency in chemical control of eucalyptus rust under field conditions. Summa Phytopathologica, v.37, n.2, p.107-112, 2011.

Originally from South America, eucalyptus rust is caused by the fungus Puccinia psidii, and has become a limiting disease for eucalyptus cultivation in Brazil, requiring the adoption of control measures, for example the chemical control. To evaluate the efficiency and economic viability of fungicides to control eucalyptus rust, a test has set up in the field. The experimental design adopted for the test has randomized blocks, $3 \times 3$ ( 3 products and 3 doses) in factorial arrangement, with $0.5,1.0$ and $1.5 \mathrm{~mL}$ or $\mathrm{g}$ of commercial product per liter of solution. The treatments were: 1-) control; 2-)

Fungicide azoxystrobin (strobilurins); 3-) Fungicide tebuconazole (triazole); 4-) Fungicide tebuconazole + trifloxystrobin (triazole + strobilurins). Four replicates were used to assess plant disease severity based on the percentage of damaged leaf area. Higher fungicide doses led to a greater reduction of the disease in the plants at 7 and 15 days after the application. The fungicide tebuconazole + trifloxystrobin at $1.5 \mathrm{~mL} / \mathrm{L}$ was the most efficient against eucalyptus rust under field conditions. The fungicide tebuconazole was the most economically viable at the three tested doses.
\end{abstract}

Keywords: Puccinia psidii; Eucalyptus; fungicides.

A atividade de base florestal, presente em quase todo o território nacional, divide-se em vários segmentos, como: celulose e papel, papelão ondulado, siderurgia a carvão vegetal, móveis e madeira processada mecanicamente, que engloba a produção de madeira serrada, painéis reconstituídos, compensados e laminados e produtos de maior valor agregado, além de vários produtos não madeireiros (14).

A área de florestas plantadas no Brasil vem crescendo em média de $2,5 \%$ ao ano nos últimos anos, atingindo um total de 6,3 milhões de hectares de florestas plantadas somente com Pinus e eucalipto, em 2009. Tanto o crescimento da área plantada como incrementos na produtividade são insuficientes para atender a demanda crescente de madeira para diferentes segmentos do setor produtivo (1).
A cultura do eucalipto é uma das mais importantes do Brasil, constituindo-se em fonte de energia e madeira renovável, além de suportar importantes processos agroindustriais para produção de papel, celulose e essências (6).

O eucalipto era considerado uma essência florestal praticamente livre de doenças até a década de 70. Entretanto, o avanço das áreas reflorestadas para regiões mais quentes e úmidas, o plantio de espécies mais suscetíveis e a utilização repetitiva de uma mesma área para plantio criaram condições favoráveis à ocorrência de doenças $(6,8)$. Dentre elas, a ferrugem causada por Puccinia psidii Winter, e o cancro, causado por Cryphonectria cubensis (sin. Crysoporthe cubensis) (Bruner) Hodges, são as mais limitantes ao estabelecimento de novos 
plantios e da condução de brotações de algumas espécies e procedências de Eucalyptus $(4,13)$.

A ferrugem do eucalipto causada pelo fungo Basidiomycota Puccinia psidii, a partir da década de noventa, vem sendo apontada como uma das principais doenças da cultura, ocasionando severos danos às plantações, com redução na produção de celulose $(4,10)$.

Epidemia é definida pelo aumento da intensidade e, ou, extensão (área geográfica) da doença em uma dada população de plantas (2). No caso da ferrugem, pode acarretar danos de até $25 \%$, em média, na produção no estado de São Paulo (7). O dano é definido como qualquer redução na quantidade ou na qualidade da produção devido a injúrias causadas pelo patógeno (11). Em condições de ambiente favorável, o patógeno infecta órgãos tenros da parte aérea, em mudas no viveiro e em plantas jovens no campo com até $3 \mathrm{~m}$ de altura, e pode causar redução de crescimento e perda de dominância apical, morte de brotações após o corte raso, bem como morte e refugo de mudas para o plantio (3). Ante ao cenário recorrente da doença em plantios seminais e clonais de eucalipto no Brasil, o estabelecimento de estratégias preventivas e mitigadoras da doença em caráter de viveiro e, principalmente, campo, consistem na premissa do manejo integrado deste importante agente impactante à eucaliptocultura no país.

Neste contexto, os objetivos deste trabalho foram: analisar a eficiência do controle químico da ferrugem do eucalipto em campo, de modo erradicativo, a partir de três diferentes fungicidas aplicados em três diferentes doses. Ademais, estabelecer critério de viabilidade econômica para os produtos e doses testados em condições de campo.

\section{MATERIAL E MÉTODOS}

\section{Caracterização do experimento}

O experimento foi conduzido no litoral Norte do Estado da Bahia, nas áreas de plantio comercial da Bahia Specialty Cellulose/Copener Florestal Ltda.

Utilizou-se o manejo de brotação para a realização deste ensaio, tendo em vista a maior quantidade de ramos novos e rebentos foliares, de maior suscetibilidade à infecção por $P$. psidii. $\mathrm{O}$ material clonal utilizado foi um híbrido suscetível de Eucalyptus grandis x Eucalyptus urophylla ("urograndis").

Este experimento foi composto por 12 tratamentos, separados em três diferentes doses de três produtos concentrados testados, considerando uma testemunha para cada dose (três testemunhas). Com isto, minimiza-se o erro de resultados, como frequentemente observado em ensaios experimentais com testemunhas absolutas. Os tratamentos utilizados encontram-se na Tabela 1.

Os tratamentos foram distribuídos em blocos ao acaso, em esquema fatorial $3 \times 3$ ( 3 produtos, 3 doses), com quatro repetições. Cada repetição foi composta por 10 plantas, totalizando, portanto, 40 plantas por tratamento. A distância entre blocos foi de cinco plantas na linha de plantio e, de três linhas de plantio entre blocos. A distância entre tratamentos de diferentes doses foi de três plantas. Separou-se três linhas de plantio, com aplicação das soluções fungicidas nas três, porém, com avaliação de severidade apenas na linha do meio.

O experimento foi conduzido no município de Inhambupe/BA, latitude: $11^{\circ} 51^{\prime} 13^{\prime \prime} \mathrm{S}$, longitude: $38^{\circ} 23^{\prime} 42^{\prime \prime} \mathrm{W}$, altitude de 233,00 metros. A idade das brotações utilizadas no presente ensaio foi de dois meses.

As parcelas experimentais encontravam-se sob condições de infecção natural por $P$. psidii nas plantas. A distribuição da
Tabela 1. Tratamentos utilizados no ensaio químico de controle de ferrugem em campo.

\section{Tratamentos}

1 Testemunha

2 azoxistrobina $0,5 \mathrm{~g} / \mathrm{L}$

3 tebuconazol $0,5 \mathrm{~mL} / \mathrm{L}$

4 tebuconazol + trifloxistrobina $0,5 \mathrm{~mL} / \mathrm{L}$

5 Testemunha

6 azoxistrobina $1,0 \mathrm{~g} / \mathrm{L}$

7 tebuconazol $1,0 \mathrm{~mL} / \mathrm{L}$

8 tebuconazol + trifloxistrobina $1,0 \mathrm{~mL} / \mathrm{L}$

9 Testemunha

10 azoxistrobina $1,5 \mathrm{~g} / \mathrm{L}$

11 tebuconazol $1,5 \mathrm{~mL} / \mathrm{L}$

12 tebuconazol + trifloxistrobina $1,5 \mathrm{~mL} / \mathrm{L}$

severidade da doença nas plantas foi previamente avaliada no intuito de verificar a uniformidade, garantindo, assim, a segurança na concretização dos resultados e menor coeficiente de variação.

Realizou-se a aplicação das soluções fungicidas nas três linhas demarcadas, posteriormente à avaliação prévia, porém, a quantificação de severidade deu-se apenas na linha do meio. Foram utilizados três produtos concentrados sistêmicos no presente experimento. Os produtos utilizados foram: 1-) Testemunha (aplicou-se água); 2-) Fungicida azoxistrobina - grupo químico estrobilurina; 3-) Fungicida tebuconazol - grupo químico triazol; 4-) Fungicida tebuconazol + trifloxistrobina - grupo químico triazol e grupo químico estrobilurina, respectivamente.

As plantas foram avaliadas previamente quanto à severidade, utilizando-se escala diagramática para determinação do percentual de área foliar lesionada (Figura 1), proposta por Masson et al. (9). Foram avaliados os cinco primeiros pares de folhas apicais de todos os ramos juvenis de cada planta, de modo a abranger todas as porções suscetíveis da planta à infecção por $P$. psidii. Foi quantificada a severidade de ferrugem em cada planta, através da ponderação dos níveis de severidade observados em cada ramo analisado. Adotouse esta metodologia de avaliação em função da ocorrência da doença restringir-se aos ramos e folhas jovens, sendo os ramos e tecidos mais velhos necrosados quando do estádio tardio de alta severidade da doença, passíveis de comprometimento dos resultados.

A avaliação prévia da doença foi realizada obtendo-se percentual de área foliar lesionada, na data de 20/11/2008. Posteriormente, realizou-se a aplicação das soluções fungicidas nas plantas utilizando-se pulverizador costal. A vazão do pulverizador costal foi devidamente ajustada para cada planta receber $50 \mathrm{~mL}$ de solução fungicida.

Foram realizadas duas avaliações semanais da severidade, posteriormente à aplicação das soluções fungicidas, nas datas de 27/11/2008 e 04/12/2008, abrangendo 7 e 15 dias pós-aplicação, respectivamente. Os resultados obtidos foram expressos em percentual de área foliar lesionada para subsequente análise da eficiência e viabilidade econômica do controle químico da ferrugem em condições de campo.

Para a análise estatística dos resultados de eficiência, os dados foram transformados em arc sen (raiz x/100), sendo expressos em percentual de área foliar lesionada. Os dados de severidade foram submetidos à análise de variância fatorial e as médias comparadas 


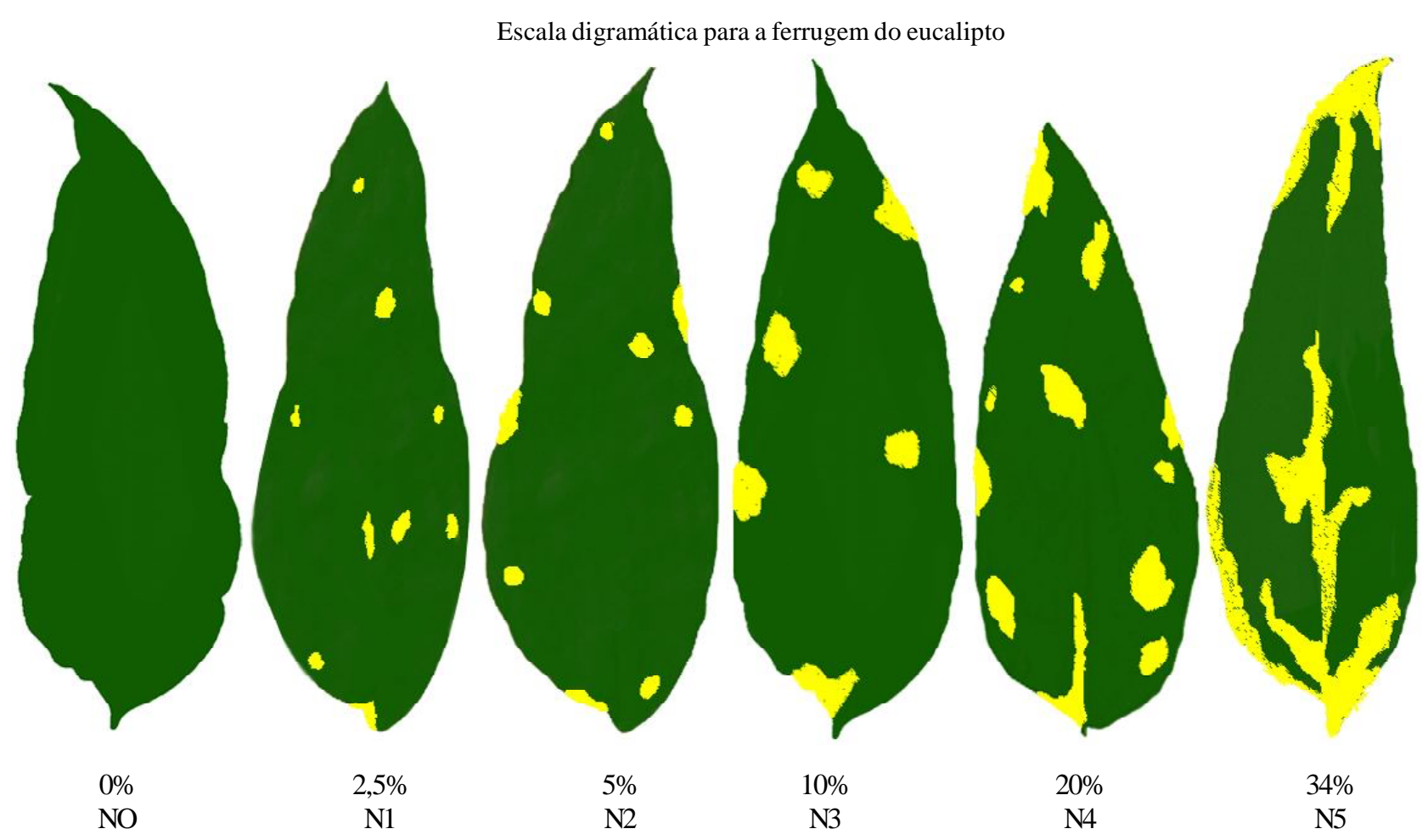

Figura 1. Escala diagramática para quantificação da severidade da ferrugem do eucalipto, expressa em percentual de área foliar lesionada (9).

entre si pelo teste de Scott-Knott $(\mathrm{p}<0,05)$, com o auxílio do software SISVAR 5.0.

\section{RESULTADOS E DISCUSSÃO}

Eficiência do controle químico sobre a ferrugem do eucalipto em campo

O efeito erradicativo variou de acordo com os tratamentos em função do tempo, sendo que a avaliação de 15 dias após a aplicação apresentou maior efeito dos fungicidas no controle da ferrugem em condições de campo, em comparação aos sete dias pós-aplicação. Verificou-se que na primeira avaliação (prévia), a severidade da doença foi semelhante, sendo estatisticamente igual para todos os tratamentos (Tabela 2). Após uma semana da aplicação das soluções fungicidas (segunda avaliação), verificou-se que houve redução da severidade da doença em termos de percentual de área foliar lesionada, sendo as médias dos valores estatisticamente diferentes do obtido nas testemunhas (Tabela 2). Todavia, observou-se diferença estatística entre os tratamentos (Tabela 2), sendo que o fungicida azoxistrobina a $0,5 \mathrm{~g} / \mathrm{L}$ foi estatisticamente igual à testemunha, os três fungicidas testados a 1,0 g ou $\mathrm{mL} / \mathrm{L}$ foram iguais entre si e diferentes da testemunha e, a $1,5 \mathrm{ml} / \mathrm{L}$, os fungicidas tebuconazol e tebuconazol + trifloxistrobina foram superiores ao azoxistrobina e à testemunha, sendo o tebuconazol + trifloxistrobina com maior efeito erradicativo sobre a doença na segunda avaliação (Tabela 2).

Da segunda para a terceira semana após a aplicação das soluções fungicidas, observou-se estabilidade da doença nos tratamentos testemunhas (tratamentos 1, 5 e 9). Houve redução da doença nos tratamentos de $0,5 \mathrm{~g}$ ou $\mathrm{mL} / \mathrm{L}$, estatisticamente diferentes da segunda avaliação. Porém, verificou-se que nos tratamentos de 1,0 $\mathrm{g}$ ou $\mathrm{mL} / \mathrm{L}$ não houve diferença estatística da segunda para a terceira avaliação, indicando que o efeito erradicativo dos produtos foi pronunciado na primeira semana pós-aplicação. Os fungicidas azoxistrobina e tebuconazol a $1,5 \mathrm{~g}$ ou $\mathrm{mL} / \mathrm{L}$ apresentaram resultados estatisticamente iguais na terceira avaliação com relação à segunda, mesmo havendo redução de percentual de área foliar lesionada (Tabela 2). Apenas o fungicida tebuconazol + trifloxistrobina a $1,5 \mathrm{~mL} / \mathrm{L}$ mostrou-se superior aos demais, reduzindo a doença a 0,31 \% de área foliar lesionada, estatisticamente diferente quando comparado à segunda avaliação, e indicando ação erradicativa sobre a doença 15 dias pós-aplicação em condições de campo (Tabela 2).

Quanto aos tratamentos na terceira avaliação, verificou-se que a $0,5 \mathrm{~mL} / \mathrm{L}$ os fungicidas tebuconazol e tebuconazol + trifloxistrobina foram estatisticamente iguais no efeito erradicativo, sendo o azoxistrobina inferior aos mesmos. Verificou-se que a $1,0 \mathrm{~g}$ ou $\mathrm{mL} / \mathrm{L}$, os fungicidas tebuconazol e tebuconazol + trifloxistrobina foram estatisticamente iguais, ambos com médias de $1,13 \%$ de área foliar lesionada, e mais eficientes do ponto de vista erradicativo em relação ao azoxistrobina, com um valor médio de $1,88 \%$. A $1,5 \mathrm{~g}$ ou $\mathrm{mL} / \mathrm{L}$, observou-se maior efeito erradicativo dos fungicidas sobre a ferrugem, sendo azoxistrobina e tebuconazol estatisticamente iguais, e tebuconazol + trifloxistrobina superior e diferente dos demais, de acordo com os dados observados na Tabela 2.

De acordo com os resultados obtidos, foram estabelecidas taxas percentuais de controle efetivo da doença em detrimento dos tratamentos adotados. Para tal, determinou-se no presente estudo, a "Taxa Percentual de Eficiência de Fungicida - \%EF", determinada pela 
Tabela 2. Efeito erradicativo de fungicidas sistêmicos no controle da ferrugem do eucalipto sob três diferentes doses, expressa em percentual de área foliar lesionada.

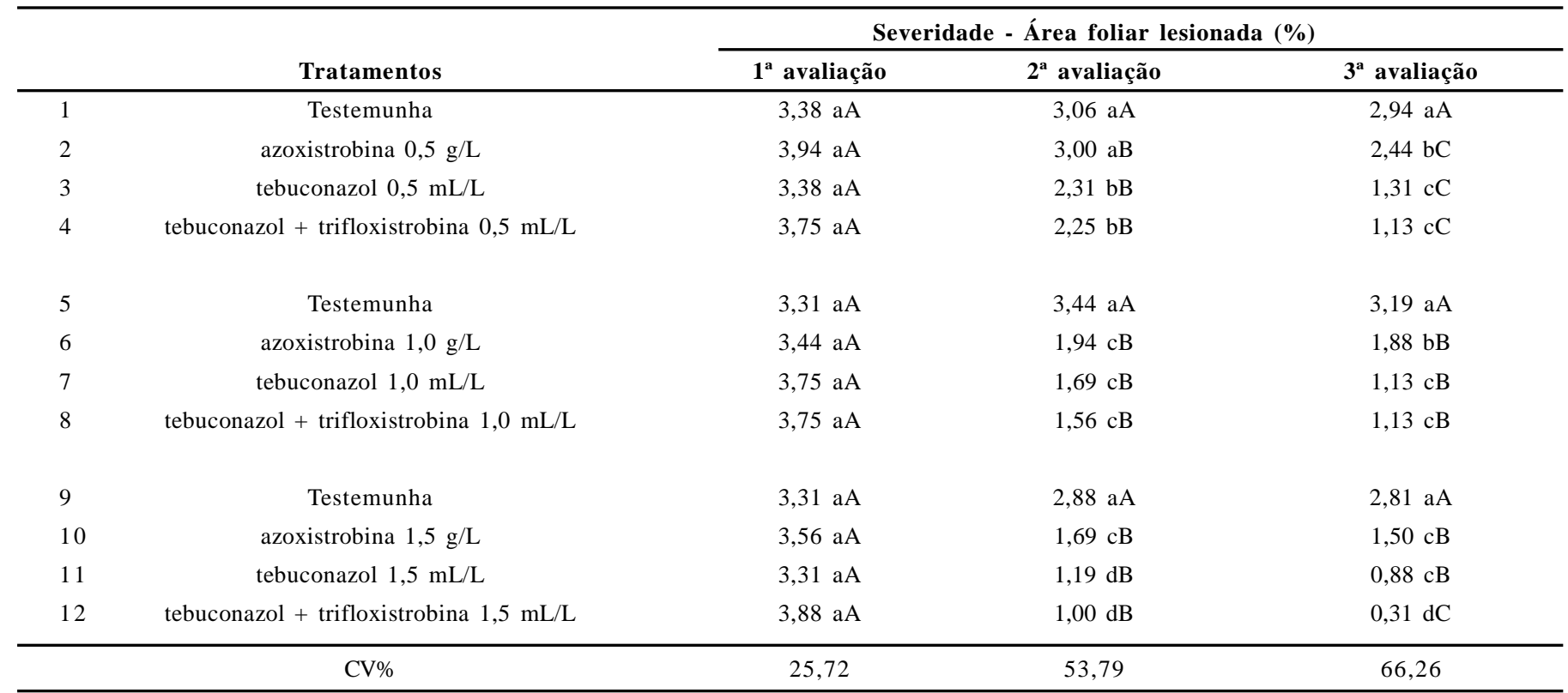

Letras minúsculas comparam os tratamentos em cada avaliação (coluna)

Letras maiúsculas comparam o mesmo tratamento nas três avaliações (linha)

Médias comparadas entre si pelo teste de Scott-Knott $(\mathrm{p}<0,05)$

Dados transformados em arc sen $(\mathrm{x} / 100)$

equação:

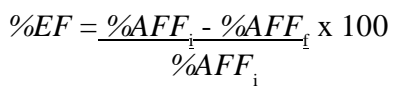

Onde:

$\% E F$ - Taxa Percentual de Eficiência de Fungicida;

$\% A F F_{i}$ - Percentual de Área Foliar com Ferrugem inicial;

$\% A F F_{\mathrm{f}}$ - Percentual de Área Foliar com Ferrugem final.

Para a aplicação da equação, é necessário que a doença seja quantificada em nível de campo, com severidade em percentual de área foliar lesionada, conforme escala diagramática (Figura 1). Calculou-se a \%EF para os tratamentos em caráter erradicativo, da primeira para a segunda avaliação, da segunda para a terceira, e efeito total erradicativo, sendo da primeira para a terceira avaliação. A Tabela 3 apresenta os resultados das taxas percentuais de eficiência de controle para cada tratamento.

Com base na Tabela 3, verifica-se que as \%EFs foram altas no primeiro intervalo semanal, ou seja, da primeira para a segunda avaliação. Os tratamentos que contemplaram a dose de $1,5 \mathrm{~g}$ ou $\mathrm{mL} / \mathrm{L}$ apresentaram as maiores taxas neste período, sendo de 52,53 $\%, 64,05 \%$ e 74,23\%, respectivamente, para os fungicidas azoxistrobina, tebuconazol e tebuconazol + trifloxistrobina. Observou-se período de proteção dos produtos quando da dose de $0,5 \mathrm{~g}$ ou $\mathrm{mL} / \mathrm{L}$, havendo valores de $\% \mathrm{EF}$ próximos da primeira para a segunda semana e, da segunda para a terceira. Isso indica que a dose dos produtos concentrados manteve-se ativa para o período de 15 dias pós-aplicação, de fato, por tratar-se de fungicidas sistêmicos, assumindo valores totais de \%EF de 38,07\%, 61,24\% e $69,87 \%$ respectivamente, para azoxistrobina, tebuconazol e tebuconazol + trifloxistrobina. Ressalta-se que nos tratamentos testemunhas (1, 5 e 9) ocorreu redução natural da doença, indicando um decréscimo da doença em nível de campo. Porém, os valores observados para os tratamentos fungicidas foram superiores e estatisticamente diferentes das testemunhas. A $1,5 \mathrm{~g}$ ou $\mathrm{mL} / \mathrm{L}, \mathrm{o}$ fungicida tebuconazol + trifloxistrobina apresentou $92,01 \%$ de $\%$ EF 15 dias pós-aplicação, seguido do tebuconazol, com 73,41\%. $O$ fungicida azoxistrobina nesta dose foi inferior aos demais fungicidas, com $\% \mathrm{EF}$ de $57,87 \%$. Ressalta-se que é necessário considerar uma $\%$ EF de $15,11 \%$ no tratamento testemunha para

Tabela 3. Taxas Percentuais de Eficiência Fungicida (\%EF) sobre a ferrugem do eucalipto, sob aplicação de três fungicidas sistêmicos em três diferentes doses.

\begin{tabular}{lcccc}
\hline & & \multicolumn{3}{c}{$\% \mathrm{EF}$} \\
\cline { 3 - 5 } & Tratamentos & 1 para 2 & 2 para 3 & 1 para 3 \\
\hline 1 & Testemunha & 9,47 & 3,92 & 13,02 \\
2 & azoxistrobina $0,5 \mathrm{~g} / \mathrm{L}$ & 23,86 & 18,67 & 38,07 \\
3 & tebuconazol $0,5 \mathrm{~mL} / \mathrm{L}$ & 31,66 & 43,29 & 61,24 \\
4 & tebuconazol + trifloxistrobina $0,5 \mathrm{~mL} / \mathrm{L}$ & 40,00 & 49,78 & 69,87 \\
& & & & \\
5 & Testemunha & $-3,93$ & 7,27 & 3,63 \\
6 & azoxistrobina $1,0 \mathrm{~g} / \mathrm{L}$ & 43,60 & 3,09 & 45,35 \\
7 & tebuconazol 1,0 mL/L & 54,93 & 33,14 & 69,87 \\
8 & tebuconazol + trifloxistrobina 1,0 mL/L & 58,40 & 27,56 & 69,87 \\
& & & & \\
9 & Testemunha & 12,99 & 2,43 & 15,11 \\
10 & azoxistrobina $1,5 \mathrm{~g} / \mathrm{L}$ & 52,53 & 11,24 & 57,87 \\
11 & tebuconazol 1,5 mL/L & 64,05 & 26,05 & 73,41 \\
12 & tebuconazol + trifloxistrobina 1,5 mL/L & 74,23 & 69,00 & 92,01 \\
\hline
\end{tabular}

1 para 2 representa primeira para segunda avaliação; 2 para 3 representa segunda para terceira avaliação; e 1 para 3 representa primeira para terceira avaliação (efeito erradicativo total). 
esta dose, ocorrendo tal taxa de redução natural, devendo os tratamentos ser analisados conjuntamente com os valores obtidos de \%EF para os tratamentos testemunhas.

Avaliando os efeitos curativos e protetor, e o tempo de absorção de fungicidas sistêmicos no controle da ferrugem do eucalipto, Zauza et al. (16) verificaram que os fungicidas azoxiztrobina, triadimenol, tetraconazol, tebuconazol e epoxiconazol + piraclostrobina apresentaram $100 \%$ de ação curativa quando aplicados até quatro dias após a inoculação. Aplicados após sete dias, apenas azoxistrobina, tebuconazol e epoxiconazol + piraclostrobina mantiveram o efeito curativo. Aos 10 dias depois da inoculação, os fungicidas reduziram a infecção, mas não controlaram totalmente a doença. Além do efeito curativo, azoxistrobina e triadimenol proporcionaram efeito protetor quando aplicados até 21 dias antes da inoculação de $P$. psidii. Ainda segundo estes autores, foi avaliado o tempo mínimo de absorção de azoxistrobina, tebuconazol, triadimenol e trifloxistrobina. Esses quatro fungicidas foram absorvidos pela planta em todos os intervalos testados - 30, 60, 90 e 120 min - e inibiram a infecção de $P$. psidii em mudas de eucalipto.

Os triazóis têm como principais características: penetração e translocação rápidas, ação curativa sobre infecções já iniciadas e reduzida perda por lixiviação (5). No caso do presente ensaio, verificou-se que os fungicidas compostos por triazóis apresentaram maior resposta na primeira semana (7 dias) comparando-se aos 15 dias. No caso da estrobilurina (azoxistrobina), verificou-se que a resposta foi semelhante aos triazóis, porém, a 0,5 g/L a tendência foi gradativa ao longo dos 15 dias. As estrobilurinas são um grupo de fungicidas sistêmicos que atuam inibindo a respiração fúngica (15). Zauza et al. (16) apontam que o controle de $100 \%$ com a aplicação de epoxiconazol + piraclostrobina até sete dias da inoculação possivelmente ocorreu pelo aumento do espectro de ação e da duração da atividade antifúngica, proporcionado pela mistura de produtos com mecanismos de ação diferentes (12). Semelhantemente, observou-se no presente estudo, em caráter de campo, que o Produto concentrado misturado (tebuconazol + trifloxistrobina) demonstrou-se eficiente em infecções tardias, havendo pústulas urediniais pouco vigorosas quando passados 15 dias.

Viabilidade econômica do controle químico da ferrugem do eucalipto em campo

Para a análise da viabilidade do controle químico, realizou-se a cotação comercial dos valores dos Produtos concentrados de mercado, em janeiro de 2009, em dois diferentes distribuidores, extraindo-se a média dos valores comerciais. Com isso, foram obtidos os seguintes valores:

Fungicida azoxistrobina - R \$445,20/Kg;

Fungicida tebuconazol - R $\$ 63,05 / \mathrm{L}$;

Fungicida tebuconazol + trifloxistrobina - R \$ 88,57/L

De posse dos valores comerciais dos produtos, realizou-se a análise de viabilidade econômica de aplicação de cada produto em cada dose. Para tal, desenvolveu-se no presente estudo a expressão "VCF - Viabilidade de Controle de Ferrugem", cuja expressão matemática é função do valor do produto concentrado vendido comercialmente, e da Taxa Percentual de Eficiência de Fungicida (\%EF). Definiu-se, portanto, a expressão de Viabilidade do Controle de Ferrugem, a saber:

$$
V C F=V p . c . \times(1 / \% E F)
$$

Onde:

$V C F$ - Viabilidade de Controle de Ferrugem;

Vp.c. - Valor comercial do Produto Concentrado, em Reais por unidade de Litro ou Kilograma $(\mathrm{R} \$ / \mathrm{L}$ ou $\mathrm{R} \$ / \mathrm{Kg})$;

$\% E F$ - Taxa Percentual de Eficiência de Fungicida.

Realizou-se a delimitação dos valores de VCF de acordo com as variáveis em questão, levando em conta o percentual ideal para redução de ferrugem quinzenal, adotado como $60 \%(\% \mathrm{EF})$ e dose padrão de intervenção de $1,0 \mathrm{~g}$ ou $\mathrm{mL} / \mathrm{L}$. Valores de VCF inferiores a 1,0 podem ser apontados como bom indicativo de viabilidade econômica de controle de ferrugem, sendo valores de VCF inversamente proporcional à viabilidade, ou seja, quanto menor o $\mathrm{VCF}$, maior a viabilidade econômica. Ademais, de acordo com pesquisas de valores de mercado de fungicidas sistêmicos, determinou-se o valor ótimo por unidade de Litro ou Kilograma de R \$60,00. Ponderou-se o rendimento do produto e seu valor de mercado, ao nível seguro de aplicação de uma quinzena, sendo que $60 \%$ de $\% \mathrm{EF}$ a um valor de mercado de $\mathrm{R} \$ 300,00 / \mathrm{L}$ ou $\mathrm{Kg}$ limitante. Dentro deste contexto, foram definidas as Classes limites de VCF com relação à viabilidade econômica, ou seja, dentro da relação custo-benefício:

Classe I: VCF < 0,6 - Viabilidade econômica de controle de ferrugem máxima e segura;

Classe II: VCF = 0,6 - Viabilidade econômica de controle de ferrugem ótima;

Classe III: $1,0 \leq \mathrm{VCF}>0,6$ - Viabilidade econômica de controle de ferrugem alta;

Classe IV: $2,5 \leq \mathrm{VCF}>1,0$ - Viabilidade econômica de controle de ferrugem aceitável;

Classe V: $5,0 \leq \mathrm{VCF}>2,5$ - Viabilidade econômica de controle de ferrugem moderada;

Classe VI: VCF > 5,0 - Viabilidade econômica de controle de ferrugem baixa e insegura.

Para a utilização dos limites acima descritos, deve-se quantificar a ferrugem do eucalipto de posse da escala diagramática para quantificação em percentual de área foliar lesionada (Figura 1), em caráter de campo.

Fungicidas capazes de reduzir quantidade de inóculo na planta, a uma taxa quinzenal de $100 \%$, com um valor comercial de $\mathrm{R} \$ 60,00 / \mathrm{L}$ ou Kg, a $1 \mathrm{~mL} / \mathrm{L}$, são considerados de viabilidade econômica ótima.

Posteriormente à definição e atribuições do termo Viabilidade de Controle de Ferrugem (VCF), juntamente com a Taxa Percentual de Eficiência de Fungicida (\%EF), realizou-se o cálculo dos valores de VCF diante dos resultados encontrados. A Tabela 4 apresenta os resultados de VCF.

Com base na Tabela 4, observa-se que para a dose de $0,5 \mathrm{~mL} / \mathrm{L}$, os fungicidas tebuconazol e tebuconazol + trifloxistrobina enquadraramse na Classe IV, com valores de VCF entre 1,0 e 2,5, representando viabilidade econômica de controle de ferrugem aceitável. Na dose de 1,0 $\mathrm{mL} / \mathrm{L}$, o fungicida tebuconazol + trifloxistrobina apresentou o mesmo VCF, tendo em vista os mesmos valores absolutos. Em contrapartida, o fungicida tebuconazol apresentou VCF de 0,90, enquadrando-se na Classe III $(1,0 \leq \mathrm{VCF}>0,6)$, sendo de alta viabilidade econômica de controle de ferrugem. Referente à dose de 1,5 mL/L, os fungicidas tebuconazol e tebuconazol + trifloxistrobina enquadraramse na Classe III $(1,0 \leq \mathrm{VCF}>0,6)$, sendo de alta viabilidade econômica de controle de ferrugem. O fungicida azoxistrobina mostrou-se inviável economicamente ao controle erradicativo de ferrugem em campo, para as três doses analisadas $(0,5,1,0$ e 1,5 g/L), enquadrando-se na Classe 
Tabela 4. Valores de Viabilidade de Controle de Ferrugem (VCF) para tratamentos compostos por três fungicidas sistêmicos, sob três diferentes doses.

\begin{tabular}{lcc}
\hline & Tratamentos & VCF \\
\hline 1 & Testemunha & \\
2 & azoxistrobina $0,5 \mathrm{~g} / \mathrm{L}$ & 11,69 \\
3 & tebuconazol $0,5 \mathrm{~mL} / \mathrm{L}$ & 1,03 \\
4 & tebuconazol + trifloxistrobina $0,5 \mathrm{~mL} / \mathrm{L}$ & 1,27 \\
& & \\
5 & Testemunha & \\
6 & azoxistrobina $1,0 \mathrm{~g} / \mathrm{L}$ & 9,82 \\
7 & tebuconazol $1,0 \mathrm{~mL} / \mathrm{L}$ & 0,90 \\
8 & tebuconazol + trifloxistrobina $1,0 \mathrm{~mL} / \mathrm{L}$ & 1,27 \\
& & \\
9 & Testemunha & 7,69 \\
10 & tebuconazol $1,5 \mathrm{~mL} / \mathrm{L}$ & 0,86 \\
11 & tebuconazol + trifloxistrobina $1,5 \mathrm{~mL} / \mathrm{L}$ & 0,96 \\
\hline
\end{tabular}

VI (VCF > 5,0), representativa de viabilidade econômica de controle de ferrugem baixa e insegura.

O efeito curativo significativo dos fungicidas aplicados até sete dias da inoculação de $P$. psidii possibilita estabelecer melhores intervalos de aplicação desses produtos (16). Fungicidas com efeito curativo inibem o desenvolvimento do haustório e, ou, crescimento micelial no interior dos tecidos (5).

Através dos resultados obtidos, pode-se estabelecer critérios de aplicação de soluções fungicidas de acordo com a severidade de ferrugem no campo. Caso as características climáticas estejam nas condições favoráveis à doença, com médias de temperaturas diárias de $20^{\circ} \mathrm{C}$, e umidade relativa do ar média igual ou superior a $90 \%$, aplicações em caráter erradicativo são de suma importância no controle da ferrugem em materiais suscetíveis, em severidade inicial (maior que 2,5\% de área foliar lesionada). Todavia, deve-se realizar o estudo de viabilidade econômica dentro do contexto do manejo integrado da ferrugem, visando aliar eficiência de produtos e custo de operação em níveis epidêmicos. Nestes níveis, o recomendado é que sejam utilizados fungicidas do grupo dos triazóis, com alternância com fungicidas compostos, caso perceba-se aumento no diâmetro de pústulas urediniais e concentração dos soros urediniais após quinze dias. A agregação de soros urediniais indica que o patógeno possa estar sofrendo alterações fisiológicas, surtindo estratégias de perpetuação da espécie via aumento na massa de esporos, cabendo o manejo da resistência do fitopatógeno através da intercalação quinzenal com fungicidas compostos, sendo parte dos ingredientes ativos do grupo estrobilurinas. No entanto, o manejo da doença com fungicidas deve receber tratamento cauteloso, avaliando-se a necessidade de aplicação a partir da severidade da doença observada em campo, ressaltando que a cultura do eucalipto não possui registro de produtos para utilização, justificando análises de caráter experimental.

\section{REFERÊNCIAS BIBLIOGRÁFICAS}

1. Abraf. Anuário estatístico 2010 (ABRAF) - Ano base 2009. Associação Brasileira de Produtores de Florestas Plantadas. 2008. Disponível em: <http://www.abraflor.org.br/estatisticas/ABRAF10BR.pdf $>$. Acesso em: 09 mar 2011.

2. Bergamin Filho, A.; Amorim, L. Doenças de plantas tropicais: epidemiologia e controle econômico. São Paulo, Agronômica Ceres, 1996. 299p.

3. Carvalho, A. O.; Alfenas, A. C.; Maffia, L. A.; Carmo, M. G. F. Avaliação do progresso da ferrugem (Puccinia psidii) em brotações de Eucalyptus cloeziana no sudeste da Bahia, de 1987 a 1981. Revista Árvore, Viçosa, v. 3, n. ${ }^{\circ}$ 18, p. 265-74, 1994

4. Ferreira, F. A. Patologia florestal: principais doenças florestais no Brasil. Viçosa: SIF, 1989. 570 p.

5. Forcellini, C. A. Fungicidas inibidores da síntese de esteróis. I. Tiazoles. Revisão Anual de Patologia de Plantas, Passo Fundo, v.2, p.335-355, 1994

6. Furtado, E. L.; Santos, C. A. G.; Masson, M. V. Impacto potencial das mudanças climáticas sobre a ferrugem do eucalipto no Estado de São Paulo. In: GHINI, R.; HAMADA, E. Mudanças climáticas: impactos sobre doenças de plantas no Brasil. Brasília: Embrapa Informação Tecnológica, 2008. p.273-286.

7. Furtado, E. L.; Santos, C. A. G.; Takahashi, S. S.; Camargo, F. R. A. Doenças de Eucalyptus em viveiro e plantio: diagnose e manejo. Jacareí, Votorantim Celulose e Papel, Unidade Florestal, 2001. 48 p. Boletim Técnico.

8. Junghans, D. T. Quantificação da severidade, herança da resistência e identificação de marcadores RAPD ligados à resistência à ferrugem (Puccinia psidii) em Eucalyptus grandis. 2000. 53 p. Tese (Doutorado em Fitopatologia) - Universidade Federal de Viçosa, Viçosa, 2000.

9. Masson, M. V.; Porcena, A. S.; Furtado, E. L. Escala diagramática para quantificação da severidade da ferrugem do eucalipto, confeccionada por imagem digital. No prelo.

10. Masson, M. V.; Furtado, E. L.; Santos, C. A. G. Zoneamento climático e ocorrência de ferrugem do eucalipto no extremo Sul do Estado da Bahia. In: Congresso Brasileiro de Fitopatologia, 40; 2007, Maringá. Anais...Maringá; 2007.

11. Nutter, F. W.; Teng, P. S.; Shokes, F. M. Disease assessment terms and concepts. Plant Disease, Davis, v. 75, p.1187-8, 1991.

12. Reuveni, M. Improved control of powdery mildew (Spharatheca pannosa) of nectarines in Israel using strobilurin and polyoxin B fungicides; mixtures with sulfur; and early bloom applications. Crop Protection, Surrey, v.20, n.8, p.663-668, 2001.

13. Ruiz, R. A. R.; Alfenas, A. C.; Ferreira, F. A.; Zambolim, L. Fungicidas protetores e sistêmicos para o controle da ferrugem do eucalipto, causadas por Puccinia psidii, Revista Ár. vore, Viçosa, v.11, p.56-65, 1987.

14. Sociedade Brasileira de Silvicultura. Fatos e números do Brasil Florestal 2008. Ano base 2007. Disponível em: <http:// www.sbs.org.br/FatoseNumerosdoBrasilFlorestal. pdf $>$. Acesso em: 18 mar 2009

15. Wu, Y.; Tiedemann, A. V. Physiological effects of azoxystrobin and epoxiconazole on senescence and the oxidative saturs of wheat. Pesticide Biochemistry and Physiology, San Diego, v.71, n.1, p.1-10, 2001.

16. Zauza, E. A. V.; Couto, M. M. F.; Maffia, L. A.; Alfenas, A. C. Eficiência de fungicidas sistêmicos no controle da ferrugem do Eucalyptus. Revista Árvore, Viçosa, v.32, n.5, p.829-835, 2008. 